\title{
EFFECT OF STIMULANTS ON GROWTH OF ADHD CHILDREN: A CRITICAL REVIEW
}

\author{
Radek Ptacek ${ }^{*}$, Hana Kuzelova, Ivo Paclt \\ Center for Neuropsychiatric Research of Traumatic Stress \& Department of Psychiatry, First Faculty of Medicine, \\ Charles University, Prague, Czech Republic \\ Received July 10, 2009; accepted September 2, 2009
}

\begin{abstract}
Attention deficit hyperactivity disorder (ADHD) is one of the most commonly diagnosed childhood psychiatric disorders manifested in almost every part of children's behavior. The most common treatment of ADHD is medication with stimulants, by specific amphetamine and methylphenidate. It is known that the treatment by stimulants may be accompanied by side effects from among decrease of appetite or changes in development as growth suppression and loss of weight which may present very serious phenomenon. Although many studies have monitored changes in growth and weight during medication, they did not provide definite results that the growth and weight suppression are caused by medication or not. According to many studies the height deficit is approximately amounted to $1 \mathrm{~cm} /$ year during the first 3 years of the treatment and can be clinically serious. Contrary to these findings some authors reported that the growth or weight changes can be a natural symptom of ADHD and not just a consequence of medication. The present article reviews key studies monitoring changes in parameters of growth in medicated children with ADHD, compares their results and suggest methodology improvements for further studies.
\end{abstract}

Key words: ADHD; Hyperactivity; Attention disorders; Stimulants; Anthropometry; Growth

\section{INTRODUCTION}

Attention-deficit and hyperactivity disorder (ADHD) is one of the most common childhood disorders, characterized by developmentally inappropriate cognitive deficits, levels of inattention and/or hyperactivity/impulsivity (Kaiser et al., 2008; Barkely \& Macias, 2005). The disorder is represented by a multiple loci of pathology with respect to atypical functional anatomy and pathophysiology. Cognitive deficits extend beyond executive functioning to include spatial, temporal, and lower-level „nonexecutive” functions. Atypical functional anatomy extends beyond frontostriatal circuits to include posterior cortices, limbic regions, and the cerebellum and pathophysiology includes dopaminergic as well as noradrenergic neurotransmitter systems (Vaidya \& Stollstorff, 2008; Fassbender \& Schweitzer, 2006; Roth \& Saykin, 2004). Evidence-based treatments for ADHD include medication, psychotherapeutic and psychosocial methods or combination of these (Kaiser et al. 2008), whereas the combination seems to be the most effective
(Jensen, 2009; So, 2008; Kaiser et al., 2008; Drtilkova, 2003; Paclt \& Florian, 1996). Despite this fact, single use of stimulants is the most frequent treatment method in common clinical practice (Barkley et al., 1999; Barkely \& Macias, 2005; Poulton, 2005). Positive effects of stimulants are supported by numerous studies (Rao et al., 1998; Spencer et al., 1998; Barkley et al., 1999; Barkely \& Macias, 2005; Poulton, 2005; Poulton \& Nanan, 2008) and the improvement appears to influence most of the core symptoms (Barkley et al., 1999; Barkely \& Macias, 2005; Poulton, 2005; Paclt et al., 2005; Paclt et. al, 2006; Paclt, 2008). However, the treatment by stimulants may be accompanied by different side effects - i.e. decrease of appetite (Satterfield et al., 1979; Kamer et al., 2000; Barkley \& Macias, 2005; Poulton, 2005; Paclt et al., 2006), insomnia (Barkley et al., 1999; Prihodova \& Nevsimalova, 2006), irritability, sadness (Setoodeh \& Teleffson, 2007) and also serious neurological problems (Barkley et al., 1999; Barkely \& Macias, 2005; Paclt, 2006; McAfee et al., 2008). It was also reported that

*Correspondence to: Radek. Ptacek, email: ptacek@neuro.cz 
long period use of stimulants can seriously influence growth (Satterfield et al., 1979; Friedman et al, 1981; Rao et al., 1998; Paclt et al., 2000; Rao et al., 1998; Drappatz et al., 2006). In this context, most of the available studies confirmed high initiatory growth deficit after beginning of the treatment (Kramer et al., 2000; Drappatz et al., 2006; Setoodeh \& Teleffson, 2007; Ptacek, et al., 2008).

Early and recent studies reported that amphetamine and methylphenidate as the most frequently used stimulants may influence decrease of growth hormone secretion (Drappatz et al., 2006; Rao et al., 1998), but due to the fast metabolic elimination of amphetamine and methylphenidate, the influence may not be considered as significant. Also periodical dropping off regular dose of drugs can be followed by growth compensation (Barkley et al., 1999; Paclt, 2008) but it is still unclear whether the growth changes are temporary or not (Poulton \& Nanan, 2008). The reason for this dilemma may be that the studies studying response of growth on stimulants are heterogeneous. According to early findings the most significant deficit was found in the treatment with dextroamphetamin (Safer et al., 1972), followed by methylphenidate (Satterfield et al., 1979) and pemoline (Friedman et al., 1981). In this context, Poulton (2005) emphasized the importance of measurement of children during the treatment, because the treatment can cause up to $1 \mathrm{~cm}$ growth deficit per year. According to Mattes and Gittelman (1983) the deficit can be even up to $3.3 \mathrm{~cm}$. Treatment in children is also commonly associated with loss of weight (Setoodeh \& Teleffson, 2007) that may be connected to the decrease of appetite (Drappatz et al., 2006; Rao et al., 1998). However the weight loss does not have to be direct result of a lower energy intake because it may be caused by endocrinological changes. With respect to these findings Spencer (1998) suggested that growth and weight changes can be a manifestation of this disorder itself and not only a manifestation of the secondary effect of the treatment. Possible relationship of growth to ADHD may be thus mediated by several potential mechanisms, including direct effect of the disorder on cartilage, altered central nervous system growth factors, and altered hepatic growth factors, all of which may be either medication-induced or disorderspecific (Shashank \& Joshi, 2002).

\section{CROSS-SECTIONAL STUDIES}

First cross-secional studies appeared in the 70's of the last century. Safer et al. (1972) monitored 29 hyperactive children treated with dextroamphetamine and methylphenidate. They compared two groups "drug holiday" (repeated time breaks in medication) and "drug continuation" (no breaks in medication). The holiday group gained about twice as much weight as the group with the continuous medication. The authors proposed that a "rebound phenomenon" occurred during the summer months. Similarly Klein et al. (1988) measured children after summer and found no group differences in height, but weight was higher in the group that had been taken off methylphenidate therapy. Two summers of being off methylphenidate treatment had a significant positive effect on height but not on weight. The results document a linkage between exposure to methylphenidate and reduction in growth velocity. Other important results were brought by the study of Kalachnik et al. (1982). They indicated that stature suppression does not occur in male children below 13 years of age when methylphenidate is used up to $0.8 \mathrm{mg} / \mathrm{kg} /$ day for one or two years and up to 0.6 $\mathrm{mg} / \mathrm{kg} /$ day for three years. This finding is supported by several following studies (Setoodeh \& Teleffson, 2007; Faraone et al., 2008) which also suggested the importance of dose level. Unfortunately this factor is not well described in most of other studies. Other important factors are pretreatment values of weight and height.

A retrospective study done by Schertz et al. (1996) examined weight loss in children with ADHD treated with stimulant medication. The aim of the study was to find possible predictors of changes in weight. These changes were found in both the methylphenidate group and the dextroamphetamine group. Conclusions of this study were that pretreatment weight is a significant predictor of weight loss in ADHD children treated with methylphenidate or dextroamhetamine. Pretreatment age, duration of treatment, and weight-adjusted dose were not found as significant predictors. Smaller or larger changes in growth or weight were found also in further studies. Within this context, Swanson et al. (1998) compared 18 studies which analyzed height and weight of 4400 children in age of 6-17 years and found that the average height was at the 51st percentile, weight at the 61 st percentile. Children treated with stimulants in this study were found to be smaller than controls. After three years, the growth suppression seemed to reach its maximum effect. Upon these findings Swanson postulated that growth monitoring should be standard practice for kids taking stimulant medication. Swanson et al. (2006) further evaluated the hypothesis of stimulant medication effect on physical growth and in their study medicated group showed average growth of $2.0 \mathrm{~cm}$ and $2.7 \mathrm{~kg}$ less than the not medicated subgroup.

Deceleration of growth in medicated children was also confirmed by MTA Cooperative Group (2004). The MTA is a cooperative treatment study performed by 6 independent research teams in collaboration with the National Institute of Mental Health and the Office of Special Education Programs of the US Department of Education, Washington, DC. The results of this group are congruently referred as MTA Group (MTA, 2004). 
MTA performed analyses to evaluate effects of changes in medication use on 14 to 24 month change scores of effectiveness (symptom ratings) and growth (height and weight measures). Results show that the medicated group has reduced height gain compared with the group that has never reported medication use. Also Charach et al. (2006) recorder weight loss and growth suppression during the treatment of 79 children, 6 to 12 years of age and the period was up to 5 years. Further significant differences were found by Lisska and Rivkees (2003), who studied 84 ADHD patients (68 boys and 16 girls) treated with methylphenidate. They found significant differences in mean height SD scores between treated children and sibling controls after 2 years of treatment. However, before the treatment heights were similar between the patients and their age matched untreated siblings, the growth delay was seen in both high and low doses (10-80 mg/day).

Above mentioned results of changes of growth were not supported by Sund and Zeiner (2002), who examined growth in children undergoing extended stimulant treatment in 91 children. 68 subjects of this group were treated with amphetamine and 23 with methylphenidate. The age interval of the group was 3-10 years. According to the results, the treatments with amphetamine or methylphenidate did not have negative effects on growth. However, some children from the amphetamine group showed weight loss during the first year of treatment. The changes in weight also were not confirmed by Zhang (2005), who analyzed 146 school age children (126 boys) with ADHD treated with methylphenidate [0.27-0.64 mg/ (kg.day)] and 29 non medicated children. According to these results age, sex, DSM-IV type and dose of methylphenidate did not contribute significantly to the variance of height. The mean height velocity from the 1st to the 4th year of age was $4.28 \mathrm{~cm} /$ year, $4.90 \mathrm{~cm} /$ year, $4.98 \mathrm{~cm} /$ year and 4.95 $\mathrm{cm} /$ year. Small but significant deceleration of height velocity was identified as a long-term side effect of methylphenidate. No influence on weight was found.

Despite the fact that significant changes in weight were not found in the two above mentioned studies, Waring et al. (2008) reported new findings. They carried out a cross-sectional analysis of 62887 children and adolescents aged 5 to 17 years of age. The children and adolescents were classified as underweight, normal weight, at risk of overweight, or overweight according to BMI for age and gender. After adjustment for age, gender, race/ethnicity, socioeconomic status, and depression/anxiety, children and adolescents with ADHD not currently using medication had up to1.5 times the odds of being overweight, and medicated children and adolescents had up to 1.6 times the odds of being underweight compared to children and adolescents without the diagnosis.
The finding that children taking stimulant medication are half as likely to be overweight as those not on the medications was supported also by Curtin (2005).

Although numerous studies, in concordance with prevalence in population, included only ADHD boys, Biederman et al. (2003) observed growth and weight differences during medication also in girls. Comparison of these studies shows that ADHD-growth association is not probably gender dependent.

\section{LONGITUDINAL AND PROSPECTIVE STUDIES}

According to numerous studies height deficits in children have been reported many times, but not many longitudinal studies were done. It is possible that the growth catch-up is related to ADHD-associated delayed maturation and is not a result of stimulant treatment. Long effect of these changes has been monitored by a few longitudinal studies or studies including adults. Accoding to Vincent et al. (1990) adolescents are not sensitive to methylphenidate. Spencer et al. (1998) also found the adult height is not influenced by this suppression of growth. Similarly, Faraone and Giefer (2007) observed 127 children in age from 6 to 12 years during 36 months of treatment with methylphenidate. The results showed that the treatment was associated with small but significant delays of growth especially in height, weight, and BMI. Faraone et al. (2008) postulate that the treatment with stimulant medication is leading to statistically significant delays in height and weight and suggest that growth deficits may be dose dependent, and may not differ between methylphenidate and amphetamine. In this relation he concludes that treatment with stimulants in childhood may reduce expected height and weight at moderate level.

Although these effects attenuate over time and some data suggest that ultimate adult growth parameters may not be affected (Faraone et al., 2008). This was confirmed also by the study of Zachor et al. (2006), who analyzed the effects of long-term psychostimulant medication on growth parameters in children with ADHD. There were 89 children measured at baseline in the interval of 3, 6, 12, 24, and 36 months. Significant weight loss was documented mostly during the first few months of the treatment. Pre-pubertal children had more significant weight loss than children during puberty. Significant changes were found over the 2 years of treatment and no long-term impact on height was noted. According to their results the growth changes in longterm stimulant therapy are not clinically significant. Most of the previous studies suggest that the stimulantassociated height deficits in ADHD are temporary and early manifestation of ADHD itself and they do not represent a complication of the therapy, and the small risk of growth lost may be a price paying for many children to gain improved learning and social function. 
Table 1. Comparison of the studies.

\begin{tabular}{|c|c|c|c|}
\hline Study & Age & Dose (mg/day) & Results \\
\hline Safer, Allen, \& Barr 1972 & NS & $\begin{array}{c}\mathrm{mph} \pm 20 \mathrm{mg} \\
\mathrm{mph} \pm 20 \mathrm{mg} \\
(+\mathrm{dex})\end{array}$ & weight loss \\
\hline Safer \& Allen, 1973 & NS & $\begin{array}{c}\mathrm{mph} \pm 20 \mathrm{mg} \\
\mathrm{mph} \pm 20 \mathrm{mg} \\
(+\mathrm{dex})\end{array}$ & growth suppression \\
\hline $\begin{array}{l}\text { Millichap \& Millichap, } \\
\text { 1975, } 1978\end{array}$ & NS & $\mathrm{mph} 10-20 \mathrm{mg}$ & no significant differences \\
\hline Kalachnik et al., 1982 & $5-10$ & $\mathrm{mph} 18.4 \mathrm{mg}$ & no significant differences \\
\hline Klein et al., 1988 & $6-15$ & $\mathrm{mph}<60 \mathrm{mg}$ & no significant differences \\
\hline Vincent et al., 1990 & adolescents & $\mathrm{mph}=\mathrm{NS}$ & no significant differences \\
\hline Schertz et al., 1996 & NS & $\begin{array}{l}\mathrm{mph}=\mathrm{NS} \\
\mathrm{dex}=\mathrm{NS}\end{array}$ & weight loss \\
\hline Spencer et al., 1998 & adolescents & $\mathrm{mph} 38 \pm 24 \mathrm{mg}$ & growth suppression \\
\hline Swanson et al., 1998 & $6-17$ & $\mathrm{mph} 14.2 \mathrm{mg}$ & growth suppression \\
\hline $\begin{array}{l}\text { Spencer, Biederman, \& Wi- } \\
\text { lens, } 1998\end{array}$ & $13-17$ & mph $19.8 \mathrm{mg}$ & growth suppression \\
\hline Sund \& Zeiner, 2002 & $3-10$ & $\begin{array}{l}\text { mph } 23.9 \mathrm{mg} \\
\text { dex } 11.9 \mathrm{mg}\end{array}$ & no significant differences \\
\hline Biederman et al., 2003 & $6-17$ & $\mathrm{mph}=\mathrm{NS}$ & no significant differences \\
\hline Lisska \& Rivkees, 2003 & NS & $\mathrm{mph} 10-80 \mathrm{mg}$ & growth suppression \\
\hline Poulton \& Cowell, 2003 & $6-18$ & $\begin{array}{l}\text { mph } 27 \mathrm{mg} \\
\text { dex } 13.7 \mathrm{mg}\end{array}$ & growth suppression \\
\hline $\begin{array}{l}\text { MTA cooperative group, } \\
2004\end{array}$ & NS & $\mathrm{mph} 34.4 \mathrm{mg}$ & growth suppression \\
\hline Zhang et al., 2005 & NS & $\mathrm{mph} 27-64 \mathrm{mg}$ & growth suppression \\
\hline Spencer et al, 2005 & $4-12$ & atomoxetine $1,8 \mathrm{mg}$ & no significant differences \\
\hline Charach et al., 2006 & $6-12$ & $\mathrm{mph}=\mathrm{NS}$ & weight loss \\
\hline Zachor et al., 2006 & NS & $\mathrm{mph}=\mathrm{NS}$ & weight loss \\
\hline Kratochvil et al., 2006 & $6-7$ & $\mathrm{amx}=\mathrm{NS}$ & $\begin{array}{l}\text { growth suppression, } \\
\text { weight loss }\end{array}$ \\
\hline Pliszka et al., 2006 & NS & $\begin{array}{l}\mathrm{mph}=\mathrm{NS} \\
\mathrm{dex}=\mathrm{NS}\end{array}$ & no significant differences \\
\hline Faraone \& Giefer, 2007 & $6-12$ & $\mathrm{mph}=\mathrm{NS}$ & no significant differences \\
\hline Swanson et al., 2006 & NS & $\mathrm{mph}=\mathrm{NS}$ & $\begin{array}{l}\text { growth suppression, } \\
\text { weight loss }\end{array}$ \\
\hline Waring et al., 2008 & $5-17$ & NS & weight loss \\
\hline
\end{tabular}

(Setoodeh \& Teleffson, 2007). Spencer et al. (1998) supported the presumption that growth changes are not only the effect of the treatment but also manifestation of ADHD. Although at this time it is not possible to compare or statistically analyze the results due to heterogeneous methodology and insufficient sample descriptions, we attempted to provide an overview of the heterogeneity of the studies in Table 1.

\section{REVIEWS}

Most known reviews of the studies of growth in children with ADHD treated with dextroamphetamine or methylphenidate were published by Poulton (2005) and Faraone et al. (2008). These reviews show that treatment with stimulant medication may lead to statistically significant delays in height and weight and dropping out may lead to normalization of growth. The authors state that many of the reviewed studies were of poor quality and despite the large number of studies, most of those failed to detect any adverse affect on growth due to stimulant medication. Despite the reviews are detailed they do not bring concrete conclusions, recomendations or explanations. They suggest providing further research but do not offer any advice for better design of studies or for clinical practice.

\section{DISCUSSION}

In summary, it is known that stimulants may cause short time growth retardation and loss of weight. Although 
many studies have been done, the methodology and observed variables are very heterogeneous and inconsistent. The studies do not lead to definite conclusions. They found that the treatment with stimulants in childhood may reduce expected height and weight. Although these effects attenuate over time, ultimate adult growth parameters are according to current opinions probably not affected. In correspondence to the previous findings, changes of height and weight are approximately $1 \mathrm{~cm} /$ year and $1 \mathrm{~kg} /$ year less than norms. From the point of view of some authors the small risk of lost centimeters may be a price worth paying for many children to gain improved learning and social function (Barkley \& Macias, 2005). Therefore for most of the parents or children the effect on growth can be clinically unimportant (Poulton, 2007), especially when improvement in behavior follows. Some data suggest that ultimate adult growth parameters may not be affected. But whether children eventually grow to normal size or not, remains a question. Because most of the studies did not monitor changes longer than three years and could not provide definitely the effect on adult height.

The findings show that growth deficit may be dose dependent as well as drug holiday dependent, but deficits may not differ between methylphenidate and amphetamine and may also appear in the treatment by atomoxetine. According to results of the current studies it is possible to conclude that there are specific and in some cases significant differences in development and statue, especially height and weight, in children with ADHD. These characteristics may be more typical for the disorder than for the treatment. The differences in results can also indicate variability in the studied groups because analyzed studies mostly focused on the question of medication and growth. Those can detect secondary effects of medication but does not say anything about the diagnosis and relations to growth itself. Many authors discuss that changes of growth and weight likely are not caused by a decrease of appetite, which is a common side effect of the treatment, but have an endocrinological reason.

Before we reviewed changes in growth in medicated ADHD children and relations between medication and growth changes, it is neccessary to also deal with the question of direct influence of ADHD itself on growth and development. According to some studies, children with ADHD may show changes in statue, growth and development independently of medication (Spencer et al., 1998). Several previous studies suggested that the stimulant-associated height deficits in ADHD are temporary and early manifestation of ADHD itself and not side effect of pharmaco-therapy (Swanson et al., 1998). The nature of the neurochemical changes associated with ADHD and their effects are still not well understood and mechanisms of its treatment are still unclear (Shashank \& Joshi, 2002).
Further weak point of the majority of the studies is a wide age range. From anthropometric point of view that presents the most serious problem of the studies, developmental disorders are always related to age specific changes in development and maturation. From this point of view seems to be important to include in further studies also children of narrower range of age, and not include children in puberty when differences may be higher. Another weak point of current findings could be that treated ADHD children were not compared with untreated children in some cases but only with healthy control subjects. From this point of view such results could be inappropriate because it suggested that ADHD itself may lead to specific changes in growth and development. Also it is needed to emphasize that the weight and height differences may be significantly influenced by socio-economical status. Unfortunately, in most of the results we can not judge these relations because the mentioned studies do not take them into account. Despite this fact it is needed to consider these factors as important parameters for further research.

Also height and weight of children's parents and born weight and height of children were not taken into consideration of the previous studies. According to these values presumptive body height can be predicted and growth zone can be determined. Growth changes or deviations could be monitored properly on the basis of these specifications, which means that seriosity of the growth changes and final height of the child can not be estimated without these parameters. These are important factors that can show more about development of ADHD children.

Aside from knowledge of child's growth zone is needed to know child's biological maturity. For example, bone age is essential information for evaluation of biological maturity, which shows if age of the child corresponds to his/her biological maturity and also indicates possibilities of children's growth. For that reason monitoring of biological maturity would be important for further research.

In this context it is needed in further researches primarily include subjects with clearly defined ranges of age and take into account also parental heights and weights, bone age and socio-economicstatus. The effect of stimulant medication on growth needs to be studied prospectively and over longer time periods looking into the causal mechanisms, the rate of physical maturation, and long term implications for final stature.

If a decision to initiate pharmacotherapy with stimulants in children is made, monitoring of growth and other parameters should be essential and also careful height and weight monitoring is necessary throughout the entire process of pharmacotherapy. The examination of these children might be a helpful approach to understand the relationship between growth and weight changes and contribution of neurophysiological, psy- 
chological and behavioral factors. In summary we could say that the problem of changes of growth and weight during medication is still not resolved and should remain in thorough scientific examination. Nevertheless according to the present results it is possible to provide concrete recommendation for clinical practice as were presented above.

\section{CONCLUSION}

This article reviewed studies on growth and weight changes during medication of ADHD. Many studies on this topic were done, however, methodology and results are very heterogeneous. The results show that medicated children mostly have weight and height loss. It is adjusted to the influence of the stimulants on growth rate, especially in the first years of the treatment. The end of the treatment is usually followed by catch-up growth but whether children eventually grow to their normal size remains a question. However changes of growth and weight may be not only a secondary effect of the treatment but specific characteristic for ADHD. Other mechanism and possibilities are being considered. Nevertheless some studies do not confirm the changes in height or weight during the treatment and changes show as insignificant. It is possible that medication may not have radical effect on growth. However even a small change in growth appeared during the treatment can be clinically significant. Reviewed studies do not bring definite results. Although consequently conclude that it is necessary to monitor properly growth and weight in stimulant treated children. The presented article brings concrete proposals for further research in this area.

\section{Acknowledgement}

This work was supported by research grant of Ministry of Health of the Czech Republic no. NR9534.

\section{REFERENCES}

Barkley, R., A., DuPaul, G., J., \& Connor, D. (1999). Stimulans. In J. S. Werry \& M. Aman (Eds.), Practitioners guide to psychoactive drugs with children and adolescents (2nd ed.). New York: Plenum.

Barkley, R., A. \& Macias, M. (2005). Attention deficit hyperactivity disorder. In R. David (Ed.) Child and adolescent neurology (3rd ed.). New York: Blackwell.

Biederman, J., Faraone, S., V., \& Monuteaux, M., C., et al. (2003). Growth deficits and attention-deficit/hyperactivity disorder revisited: impact of gender, development and treatment. Pediatrics, 111, 1010-16.

Charach, A., Figueroa, M., \& Chen, S., Ickowicz, A., Chachar, R. (2006). Stimulant Treatment Over 5 Years: Effects on Growth. Journal of the American Academy of Child and Adolescent Psychiatry, 45, 415-421.

Curtin, C., Bandini, L., G., \& Perrin, E., C., Tybor, D., J., Must, A. (2005). Prevalence of overweight in children and adolescents with attention deficit hyperactivity disorder and autism spectrum disorders: a chart review. BMC Pediatrics, 5, 48.
Drappatz, J., Khwaja, O., S., \& Neovius, M., Sarco, D., S. (2006). Growth in Children with $\mathrm{AD}(\mathrm{H}) \mathrm{D}$ Treated with Stimulant Medications: A Meta-Analysis. Pediatric Academic Societies Annual Meeting, 4885458.

Drtilkova, I. (2003). Ucinnost nestandardnich postupu lecby u deti s ADHD. [Effect on non-standard approaches to ADHD treatement]. Ceska a slovenska Psychiatrie, 99, 317 - 323.

Faraone, S. \& Giefer, E. (2007). Long-Term Effects of Methylphenidate Transdermal Delivery System Treatment of ADHD on Growth. Journal of the American Academy of Child \& Adolescent Psychiatry, 46, 1138-1147.

Faraone, S., V., Biederman, J., \& Morley, C., Spencer, T., J., (2008). Effect of stimulants on height and weight: a review of the literature. Journal of the American Academy of Child and Adolescent Psychiatry, 47, 994-1009.

Fassbender, C. \& Schweitzer, J., B. (2006). Is there evidence for neural compensation in attention deficit hyperactivity disorder? A review of the functional neuroimaging literature. Clinical Psychology Review, 26, 445-65.

Friedmann, N., Thomas, J., \& Carr, R., Elders, J., Ringhdahl, J., Roche, A. (1981). Effect on growth in pemoline-treated children with attention deficit disorder. American Journal of Diseases of Children, 135, 329-332.

Jensen, P., S. (2009). Review: methylphenidate and psychosocial treatments either alone or in combination reduce ADHD symptoms. Evidence-Based Mental Health, 12, 783-800.

Kaiser, N., M., Hoza, B., \& Hurt, E., A. (2008). Multimodal treatment for childhood attention-deficit/hyperactivity disorder. Expert Review of Neurotherapeutics, 8, 1573-83.

Kalachnik, J., E., Sprague, R., L., \& Sleator, E., K., et al. (1982). Effect of methylphenidate hydrochloride on stature of hyperactive children. Developmental Medicine \& Child Neurology, 24, 586-95.

Klein, R., G., Landa, B., \& Mattes, J.,A., et al. (1988). Methylphenidate and growth in hyperactive children. A controlled withdrawal study. Archives of General Psychiatry, 45, 1127-30.

Kramer, J., R., Loney, J., \& Ponto, L., B., et al. (2000). Predictors of adult height and weight in boys treated with methylphenidate for childhood behavior problems. Journal of the American Academy of Child and Adolescent Psychiatry, 39, 517-24.

Kratochvil, C., J., Wilens, T., E., \& Greenhill, L., L, et al. (2006). Effects of long-term atomoxetine treatment for young children with attention-deficit/hyperactivity disorder. Journal of the American Academy of Child and Adolescent Psychiatry, 45, 919-27.

Lisska, M., C. \& Rivkees, S.,A. (2003). Daily methylphenidate use slows the growth of children: a community based study. Journal of Pediatric Endocrinology \& Metabolism, 16, 711-8. Mattes, J., A. \& Gitelmann, R. (1983). Growth of hyperactive children on maintenance regimen of methylphenidate. Archives of General Psychiatry, 40, 317-21.

McAfee, A., T., Holdridge, K., C., \& Johannes, C., B., Hornbuckle, K., Walker, A., M. (2008). The effect of pharmacotherapy for attention deficit hyperactivity disorder on risk of seizures in pediatric patients as assessed in an insurance claims database. Current Drug Safety, 3, 123-31.

Millichap, J., G. \& Millichap, M. (1975). Letter: Growth of hyperactive children. The New England Journal of Medicine, $292,1300$. 
Millichap, J., G., (1978). Growth of Hyperactive Children Treated with Methylphenidate. Journal of Learning Disabilities, 11, 567-570.

MTA Cooperative Group, (2004). National Institute of Mental Health Multimodal Treatment Study of ADHD Follow-up: changes in effectiveness and growth after the end of treatment. Pediatrics, 113, 762-9.

Paclt, I., Ptacek, R., \& Florian, J. (2006). Hyperaktivita [Hyperactivity]. Praha: Vzdelavaci institut ochrany deti.

Paclt I. \& Florian J. (1996). Deficit pozornosti u hyperaktivnich deti [Deficit of attention in hyperactive children]. Ceska a slovenska psychiatrie, 1, 23-40.

Paclt I., Uhlíkova P., \& Koudelova J., Bauer P., Vaneckova M. et al. (2000). Biological markers of the hyperkinetic syndrome in children of age 6 to 10 years. European Psychiatry, 15, 385.

Paclt, I.(2008). Hyperkyneticka porucha chovani [ADHD]. Praha: Grada.

Pliszka, S., R., Matthews, T., L., \& Braslow, K., J., Watson, M., A. (2006). Comparative effects of methylphenidate and mixed salts amphetamine on height and weight in children with attention-deficit/hyperactivity disorder. Journal of the American Academy of Child and Adolescent Psychiatry, 45 (5), 520-6.

Poulton, A. \& Cowell, C.,T. (2003) Slowing of growth in height and weight on stimulants: a characteristic pattern. Journal of Paediatric and Children Health, 39, 180-5.

Poulton, A. (2005). Growth on stimulant medication; clarifying the confusion: a review. Archives of General Psychiatry, 90, 801-806.

Poulton, A. (2007). Effect of long-term treatment with stimulant medication on growth? Journal of American Acadady of Child and Adolescent Psychiatry, 46, 305-6.

Poulton, A., S. \& Nanan, R. (2008). Prior treatment with stimulant medication: a much neglected confounder of studies of growth in children with attention-deficit/hyperactivity disorder. Journal of Child and Adolescent Psychopharmacology, 18, 385-7.

Ptacek, R., Kuzelova, H., \& Paclt, I., Zukov, I. (2008). Effect of medication on anthropometric characteristic of ADHD children. Ceska a Slovenska Psychiatrie, 104, 415-419.

Prihodova, I. \& Nevsimalova, S. (2006). Spanek a porucha pozornosti s hyperaktivitou - souhrn soucasných poznatků [Sleep and ADHD - review]. Ceska a slovenska Psychiatrie, 102, 80-84.

Rao, J., K., Julius J., R., \& Breen, T., J., Blethen, S., L. (1998). Response to Growth Hormone in Attention Deficit Hyperactivity Disorder: Effects of Methylphenidate and Pemoline Therapy. Pediatrics, 102, 497-500.

Roth, R., M. \& Saykin, A., J. (2004). Executive dysfunction in attention-deficit/hyperactivity disorder: cognitive and neuroimaging findings. The Psychiatric Clinics of North America, 27, 83-96.

Safer, D., J., Allen, R., P., \& Barr, E. (1972). Depression of growth in hyperactive children on stimulant drugs. The New England Journal of Medicine, 287, 217-220.

So, C., Y., Leung, P., W., \& Hung, S., F. (2008). Treatment effectiveness of combined medication/behavioural treatment with chinese ADHD children in routine practice. Behaviour Research Therapy, 46, 983-92.
Satterfield, J., H., Cantwell, D., P., \& Schell, A., Blaschke, T. (1979). Growth of hyperactive children treated with methylphenidate. Archives of General Psychiatry, 36, 212-217.

Schertz, M., Adesman, A., R., \& Alfieri, N., E., Bienkowski, R., S., (1996). Predictors of weight loss in children with attention deficit hyperactivity disorder treated with stimulant medication. Pediatrics, 98, 4 (1), 763-9.

Setoodeh, A. \& Teleffson, S., (2007). Attention Deficit Hyperactivity Disorder and Growth. Iranian Journal od Pediatrics, 17, 183-187.

Shashank, V. \& Joshi, M., D. (2002). ADHD, Growth Deficits, and Relationships to Psychostimulant Use Pediatrics in Review. Henry M. Adam, MD, Editor, In Brief, 23, 67-68.

Spencer, T., Biederman, J., \& Wilens, T. (1998). Growth deficits in children with attention deficit hyperactivity disorder. Pediatrics, 102, 501-506.

Sund, A., M. \& Zeiner, P. (2002). Does extended medication with amphetamine or methylphenidate reduce growth in hyperactive children? Nordic Journal of Psychiatry, 56, 53-7.

Swanson, J., M, Sergeant, J., A., \& Taylor, E., Sonuga-Barke, E., J., S., Jensen, P., S., Cantwell, D., P. (1998). Attentiondeficit Hyperactivity Disorder and Hyperkinetic Disorder. The Lancet, 351, 429-433.

Swanson, J., Greenhill, L., L., \& Wigal, T., Kollins, S., H., Stehli-Nguyen, A., Davies, M., Chuang, S., Vitiello, B., Skrobala, A., M., Abikoff, H., Oatis, M., McCracken, J., McGough, J., J., Riddle, M., Ghuman, J., Cunningham, C., Wigal, S. and the PATS Group (2006). Stimulant-Related Reductions of Growth Rates in the PATS. Journal of the American Academy of Child and Adolescent Psychiatry, 45, 130413.

Vaidya, C. J. \& Stollstorff, M. (2008). Cognitive neuroscience of Attention Deficit Hyperactivity Disorder: current status and working hypotheses. Developmental Disabilities Research Reviews, 14, 261-7.

Vincent, J., Varley, C., K., \& Leger, P., (1990). Effects of methylphenidate on early adolescent growth. The American Journal of Psychiatry, 147, 501-2.

Waring, M., E. \& Lapane, K., L. (2008). Overweight in Children and Adolescents in Relation to AttentionDeficit/Hyperactivity Disorder: Results From a National Sample. Pediatrics, 122, e1-e6.

Zachor, D.,A., Roberts, A.,W., \& Hodgens, J.,B., Isaacs, J.,S., Merrick, J. (2006). Effect of long-term psychostimulant medication on growth of children with $\mathrm{AD}(\mathrm{H}) \mathrm{D}$. Research of Developmental Disabilities, 27, 162-74.

Zhang, H., Du., M., Zhuang., S., \& Liu, M., (2005) Influence of methylphenidate on growth of school age children with attention deficit hyperactivity disorder. Zhonghua Er Ke Za Zhi. Chinese Journal of Pediatrics. 43, 723-5. 